\title{
Facing Business-IT-Alignment in Healthcare
}

\author{
Mike Krey \\ School of Management and Law \\ Zurich University of Applied Sciences \\ Winterthur, Switzerland \\ Mike.Krey@zhaw.ch
}

\begin{abstract}
The ongoing reform efforts and an aftermath of increasing regulation in the Swiss healthcare sector make it imperative for hospitals to develop strategies to work more efficiently and have better control over their medical, nursing, and administrative processes. These endeavors make hospitals to enhance and integrate concepts of Business-IT-Alignment and IT Governance, IT Risk management, and IT Compliance (IT GRC). This paper proposes a novel method for the management of IT with respect to closely-meshed organizational and social structures within hospitals. One key contribution of this method is its hybrid approach to combine collective know-how of the CObIT 5 framework with an iterative process model approach. The application of this method under realworld conditions within different Swiss hospitals has led to a positive outcome whereby all hospitals concurred that the method allows for the adoption of IT GRC principles while taking into consideration the individual styles and patterns of behavior.
\end{abstract}

\section{Introduction}

The demographic development of the society, the medical technical progress, and the change of values are faced with limited resources for health care. Legislative reform efforts, for that reason primarily aim at the increase of productivity within health care, while ensuring the quality of care, however, the therein justified changed conditions issue continually a challenge to actors in the hospital market, which make it highly dependent on the political priority of the day. Central catalyzer of these changes is the setup of incentives in inpatient care by diagnostic related groups (DRGs) in many European countries [21] (p.14). Since 2009, hospitals in Switzerland have been transitioning to a new remuneration approach providing case-based payments. The 'SwissDRG' is being introduced in 2012 and is becoming the dominant payment mechanism for hospitals in
Switzerland. Motivated by on-going reform efforts in the Swiss health care sector, for the affected hospitals it is necessary to develop concepts to work more efficiently and have control over their medical, nursing, and administrative processes.

When it comes to enhancements of the treatment chain, IT has proven to be a driver for improving process quality such as patient records were collected and communicated more easily across admitting physicians or medical and nursing staff was relieved from compulsory documenting tasks. The efficient use of IT thereby has shown a direct effect on the quality of care and patient safety [9] (p.64). This endeavor requires, besides a vast understanding of related medical, nursing, and administrative processes, a proper utilization of given IT resources, the ability to deal with innovation as well as far-sighted alignment of IT issues with hospital objectives. This calls for effective IT governance. Therefore, 'an integrated and comprehensive approach to the alignment, planning, execution and governance of IT and its resources' is becoming 'critical to more effectively align, integrate, invest, measure, deploy, service and sustain the strategic and tactical direction and value proposition of IT' supporting departments and clinics within the hospital [28]. As shown in other developed countries, reforms beginning at the hospitals inside show a tremendous potential for improvement, promising optimization effects by transforming existing (organizational) structures, consolidating provided services (specialization) and a more efficient use of information technology (IT) [24] (p.208). Nevertheless, IT causes the potential for many risks, which may disrupt operations and may lead to unintended consequences within the patient's treatment. In addition, IT is permanently reliant on certain federal and cantonal laws and regulations. This approach to Business-IT-Alignment in the hospital environment is the subject of this work. 


\subsection{Problem Statement and Objectives}

The difficulties to deal with in order to set up the Swiss health care system for the future are multilayered and complex and came from two directions: the Swiss (1) hospital environment and the (2) nature of Business-IT-Alignment and IT GRC approaches. Given an aging society, other challenges to be met by the endeavor toward a fundamental reorganization of the healthcare sector were investigated such as (1) legal restraints caused on Switzerland's federal structure with a complex system of powers and responsibilities [16], (2) the political tradition of direct democracy and governance through consensus [4], (3) closely-meshed organizational and social structures within the hospital and between its stakeholders [18]; [20]; [34], and (4) an underrepresented standing of the IT department characterized by over the years increased heterogeneous IT systems [20]. The functional organization in hospitals is characterised by a hierarchical tripartite division mostly performed according to given jobs or varieties of provided services. Medical care, nursing service, and administration are the prevailing job classifications, which influence to a great extent the organizational design. In practice, the functional organization causes not only physical separation of the departments, but, more often, a "life of its own" caused by partialautonomous decision-making [20]. Most of the clinical divisions have their own divisional director usually staffed by a senior consultant, their own nursing care, and their own administrative staff, along with their own information systems and budget responsibility. Considering the role of IT in the functional organization, it becomes obvious that IT is usually organized around the administration which reports to the director of finance or infrastructure and, thus, is considered a support function as it is not directly represented in the hospital management. The demand for IT integration challenges the traditional organization of the hospital as an entity divided by politics and competences according to medical functions. In the past, this has led to a monolithic information island with a great number of point-to-point connections between vast amounts of specialized applications across the hospital, representing the prevailing fact that hospitals today are still not considered one entity, but rather as a collection of fragmented, mostly autonomous acting entities with departmental targets, budgets, and personnel responsibilities.

On the other hand, a range of best practices, proprietary frameworks as well as standards and norms have been developed, which are also summarized in a stricter or broader sense under the topic of Business-
IT-Alignment. Notably, these frameworks are not alternative treatments of the same issue, and indeed, there is considerable overlap between them, which make a clear assignment to the individual aspects of Business-IT-Alignment more difficult. Most of the approaches lack methodical sound validity, claimed scientific rigor, and merely provide vague hints about their underlying conceptions and structures [27].

Given these complexities in both the hospital environment as well as in the field of Business-ITAlignment, a 'one size fits all' approach is questionable and calls for a profound approach to the adoption of Business-IT-Alignment principles, considering given conditions, particularities, and constraints. Although the research work at hand focuses on the Swiss healthcare system, it may be applicable to different countries that share the same kinds of problems. Based on the research motivation and the design-oriented objective of this research work, the following research question is addressed:

'How shall a method be designed and constructed with respect to the lack of expertise dealing with Business-IT-Alignment principles, the IT's underrepresented influence on decision-makings, the considerable fragmentation of the hospital organization, and the advance towards incremental changes for the purposes of generating valuable benefits for all stakeholders and contributing to ongoing reform efforts in the hospital environment?'

The method to be developed is understood as a structured guideline, which aims at enabling IT executives in hospitals to achieve greater value in the planning, implementation and control of IT GRC issues. In order to develop the method, two subordinated tasks are performed: (1) design and (2) construction of the method (cf. Figure 1). Outcome of the design task of the method is a meta-model based on the method engineering approach by [13]. The construction of the method takes up on the designed framework and applies the underlying meta-model and the elements specified therein to the context of Business-IT-Alignment in the hospital environment. The construction of the method entails a content model and related concepts such as a process and assessment model ensuring that experts form the hospital environment can more likely understand and implement the method.

The paper at hand is structured as follows: In the second section the status and spread of Business-ITAlignment and IT GRC in healthcare are presented. In Section 3 the meta-model is discussed. The related content model for the adoption of Business-ITAlignment is outlined in Section 4. Section 5 discusses the evaluation of the method under real-world conditions in three Swiss hospitals. In the final section, 
conclusions are drawn and an outlook on further research is given.

\section{Business-IT-Alignment and IT GRC in the Health Care Sector}

Although the concepts of Business-IT-Alignment and IT GRC are widely accepted, different definition approaches focus on certain aspects, which make a commonly agreed understanding even more desirable [5]; [14]; [26]. The approaches by [19] and [25] consider GRC as a strategic and continuous management process emphasizing the government tasks needed to improve operations. The Open Compliance and Ethics Group (OCEG) combined the previously mentioned aspects, outlining that 'GRC is a system of people, processes and technology that enables an organization to understand and prioritize stakeholder expectations; set business objectives congruent with values and risks; achieve objectives while optimizing risk profile and protecting value; operate within legal, contractual, internal, social and ethical boundaries; provide relevant, reliable and timely information to appropriate stakeholders; and enable the measurement of the performance and effectiveness of the system' [23].

One of the few academically motivated definition approaches was provided by [26], who conducted a comprehensive review on understandings to GRC putting the different aspects together. Their approach was iteratively modified and validated by a great number of GRC experts. They finally defined GRC as 'an integrated, holistic approach to organization-wide governance, risk and compliance ensuring that an organization acts ethically correct and in accordance with its risk appetite, internal policies and external regulations through the alignment of strategy, processes, technology and people, thereby improving efficiency and effectiveness' (p.113). This definition approach was later used by the authors as a basis for deriving a frame of reference for GRC research.

Beside the great struggle for a common definition, related contributions can be found in both academia and practice. However, the actual demand has been predominantly boosted by the business itself namely large corporations and affiliated industry such as accounting firms, technology vendors, analysts and consultants and actually has become object of research in the aftermath [27]. That inverse approach has possibly contributed to the fact that in comparison to the individual consideration of governance, risk and compliance the academic research for integrated GRC can be classified as underdeveloped [14]. Two recent literature reviews investigating publications on GRC grounded in academia and practice from 2004 to 2016, revealed in total 120 contributions [26] (p.109); [14]. Out of these contributions, even eight studies were attributed to academic research. According to the vague understanding and diversity of interpretations found in literature, it is necessary to clarify the concept of Business-IT-Alignment and IT GRC in the context of the hospital environment.

IT governance provides hospitals with related roles and responsibilities, such as an IT board and IT steering committee. The established committees may consist of hospital and IT executives providing the organizational and leadership structures through which IT operates, preparing and prioritising decisions to be made for the strategic planning of IT capabilities, or defining the field of duties of the IT manager.

IT risk management is more than a single task on a hospital board's agenda. A comprehensive risk management process provides the hospital management with the information needed to take steps against financial and operational loss caused by potential vulnerabilities. Consequently, related management questions, such as "what is the quantified risk potential and the related harm in case that the HIS (hospital information system) is unavailable?" can be answered. With the help of downtime estimation, an approximation of the longest acceptable downtime that the business (e.g. radiology department) can endure while still remaining viable is assessed.

IT compliance, on the other hand, requires that IT in hospitals acts in accordance with federal and cantonal laws and regulations, such as the Data Protection Act, and that internal policies and specifications are carried out correctly. As a result, related laws and regulations focus on, among other things, obligations towards documentation of care or the way of dealing with sensitive patient data. The obligations require, for example, that every patient record entry is dated and its author is clearly identifiable or that the collection and processing of patient data is allowed only in relation to its indicated purpose.

Pointing out the demand for a hospital-specific approach for the adoption of IT GRC, the spread of its principles in the hospital environment is discussed. Although the separated elements of IT GRC are widely accepted, applied, and empirically validated in several in industries, proving positive impact on enterprise effectiveness, IT GRC is less widespread in the hospital environment.

The author of this contribution conducted a survey in order to investigate the hospital environment in Switzerland with regard to the spread of Business-ITAlignment and IT GRC principles [20]. The survey 
covered nearly $35 \%$ of all general hospitals and $66 \%$ of all beds according to the latest annual report by the Federal Statistical Office [4]. The results of the survey are the basis for identifying the 'problem' and additionally provide fruitful insights into the structure, behavior, and processes within in the health care sector. In addition to the conducted survey, two additional reports were published in the meanwhile investigating the state-of the art of IT governance and types of IT decision-making in German hospitals [20] and exploring the acceptance of IT service management in hospitals in Germany, Slovakia, South Tyrol (Italy) and Switzerland [16]. Both studies represent valuable sources gaining deeper understanding of the challenges to overcome.

[18] conducted semi-structured interviews with IT executives in public, private, and non-profit hospitals in Germany. They used the concept of IT decision domains by [33] as a frame of reference extracting related research questions of their empirical study. In the work by [16] structured interviews with CIOs and IT executives in Austria and its neighboring regions were conducted investigating the extent to which IT service management especially the well-known standard ITIL is recognized and adopted in the hospital environment.

The investigation by [20] revealed that IT GRC in health care is all too often seen as a realm and in the sole responsibility of the CIO and the IT department. The findings proved that IT GRC has not permeated sufficiently into the executive management of many hospitals, especially the public ones. Sixty-three per cent of hospitals $(n=15)$ surveyed believed that only one-fifth of their business managers could explain their IT GRC arrangements [20]. Truly engaging executive management in this field has the potential to align business priorities, create more transparency over risk management, and bridge the communication gap [15].

The majority of the CIOs replied $(n=16)$ that the health care sector is a complex and heterogeneous economic sector and cannot be compared to other industry sectors where CObIT [11] and other IT governance frameworks have been successfully applied. Organizational structures, legal restraints, and over the years, increased heterogeneous IT systems are just a few aspects making the health care sector a sensible field for the implementation of IT GRC. Therefore, health care requires a specific attention on the status of IT and organization innovation of the hospital. To a similar conclusion came the study by [16]. Their investigation on the acceptance and spread of IT services across hospitals revealed that the concept of IT services management and the utilization of related frameworks are still not widely recognized in hospitals. Only $21 \%(n=3)$ of the surveyed Swiss hospitals already have ITIL or parts of it implemented. However, fifty per cent $(n=7)$ of the IT executives in Switzerland revealed that they do not plan any ITIL initiative to be implemented in the next two years. [16] concluded that this situation is not exclusive for Switzerland but rather can be found in other neighboring countries as well. Exploring the reasons for the reserved attitude towards IT service management the study yielded that among others different priorities, missing motivation and budget constraints have mentioned as the three major obstacles. In summary, the work by [16] in dictated that IT executives have a high demand for guidance implementing ITIL.

Although hospitals are aware of a need for change and signs of improvement can be seen, the idea of business-IT alignment has not yet been fully implemented in most hospitals. However, the findings by [20] indicated that, overall, private hospitals are more alive to the integration of Business and IT and thus confirming the strategic importance of IT is the challenge management needs to tackle.

In line with the surveys by [16] reasons for a less pervasive spread of IT GRC principles can be structured into four main categories, which represent at the same time the greatest barriers to successful convergence of IT:

- Lack of expertise (limited knowledge, methodical and technical support for IT GRC principles, etc.)

- Lack of resources (budget constraints, limited personnel resources, focus on medical processes, etc.)

- Lack of motivation (perception of insufficient benefit or demand, unfavorable ratio of costs and benefits, individual and organizational resistance to changes, lacking 'level of suffering' caused on guaranteed funding by the cantons, missing competitive constraints in the hospital market, etc.)

- Lack of reputation of IT (business priorities are in the foreground, complexity of business processes, cost-center, etc.)

Based on the outlined barriers, in the next section, insights on the relation between the meta-model and content model are given. The method to be developed is understood as a structured guideline, which aims at enabling IT executives in hospitals to achieve greater value in the planning, implementation and control of IT GRC issues. In order to develop the method, two subordinated tasks are performed: (1) design and (2) construction of the method (cf. Figure 1). Outcome of the design task of the method is a meta-model based on the method engineering approach by [13]. This metamodel is presented in the next section. 


\section{Meta-Model}

\subsection{Metaization Principle}

A model can be an instance of a meta-model and at the same time can be used 'as a meta-model of another model in a recursive manner' [22] (p.18). Consequently, various hierarchies of model levels exist, 'each (except the top) being characterized as an 'instance of the level above' [3] (p.38).

The 'metaization principle' [32] for this research work follows the linguistic meta modelling approach describing three hierarchy levels ( $\mathrm{L}_{0}$ to $\mathrm{L}_{2}$ ) (cf. Figure 1 ). The meta-model on level $\mathrm{L}_{2}$ is abstract in nature and determines the 'framework' of the method representing related method elements and their relations. Level $\mathrm{L}_{1}$ takes up on the designed framework and applies the underlying meta-model in terms of 'instance-of' to the context of IT GRC in the hospital environment representing a 'content model' (Section 4). Ensuring that the environment can more likely understand the objectives and courses of action of the method, the content model (Level $\mathrm{L}_{1}$ ) consists amongst others of activities, tasks, and techniques allowing for the actual application within a certain hospital corresponding to the artefact type 'instantiation' (Level $\mathrm{L}_{0}$ ). The instantiation arises in the context of this research work as an outcome of the evaluation phase (Section 5) and thus has a strong relation to the given hospital environment [2]; [3]. Figure 1 illustrates the relation between the method to be developed, consisting of a meta-model and a content model, and the instantiation according to the approach by [2] (p.10).

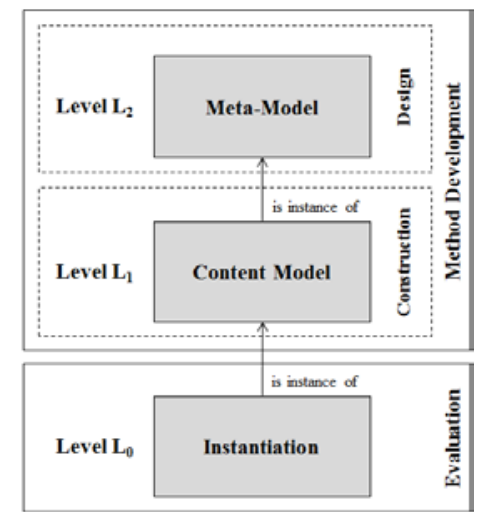

Figure 1: Metaization principle according to the linguistic meta-modelling approach, adapted from [2] (p.10)

The actual novelty of the method development primarily lies within the design task represented through the meta-model $\left(\mathrm{L}_{2}\right)$, rather than the application of existing principles in the field of IT GRC within the construction of the artefact $\left(\mathrm{L}_{1}\right)$.

\subsection{Elements of the Meta-Model}

The different method elements within the metamodel $\left(\mathrm{L}_{2}\right)$ are modelled according to the UML 2.4 specification applying related style guidelines according to [22] (p.120). All relevant UML 2.4 elements, their description, and the notation utilized for the meta-model are summarized. The underlying metamodel of the method is based on the approach by [15]. His approach is characterized by universal applicability and shows a broad acceptance in the IS world, as it has been applied by various researches for different purposes and therefore promises a suitable base for the adaptation to requirements within the context of IT GRC in the hospital environment. In order to demonstrate validity and increase the acceptance of the meta-model, the approach follows the goals of formal specification in terms of accepted modelling principles proposed by [7] (p.436); [22] (p.21).

As the underlying approach by [13] contains generic elements, a purposive adaption for this research work is needed. For this reason, the following adjustments are carried out (cf. Figure 2):

- Cardinalities are inserted between the entities in order to underline the significance and rigor of the meta-model and contribute to the principles of clarity and systematic design.

- The following elements are added in comparison the original approach: The (1) 'process model' and (2) 'phase' element are added to express the specific order through which the activities and tasks are performed. The (3) 'organizational unit' and (4) 'stakeholder' elements are modelled contributing the fact that IT GRC is a relatively new issue in the hospital environment and that the business needs to be involved. The stakeholders such as the various divisional directors or the IT manager are performing various and sometimes overlapping roles. In comparison to the Gutzwiller approach [15], the generalization of the technique element indicates the more specialized consideration of tools and systematic knowledge performing a task structuring them into a (5) 'soft technique' and (6) 'formal technique' element. In addition, a new relationship between activity and technique, emphasizing the guiding characteristic and providing the method user with a structure for thoughts and actions, replaces the original relationship 'technique provides guidance for generating a result'. Systemizing complexity, the (7) 'IT GRC area' element, the (8) 'assessment scope' element, the (9) 'assessment goal' element 
and the (10) 'assessment level' element allow a granular and separate consideration of related issues according to the hospital's individual reform efforts and intended benefits. Demonstrating the openness of the method towards existing frameworks in the field of IT GRC the (11) 'best practice process' and (12) 'IT GRC best practice' element are included into the model. Contributing to the claimed monitoring of performances caused by IT GRC initiatives the (13) 'best practice goal' and (14) 'best practice metric' element are modelled.

- Contributing to the fragmented organizational structures with the hospital environment the role element is hierarchically structured allowing that certain roles can be bundled making the establishment of board or committee structures possible.

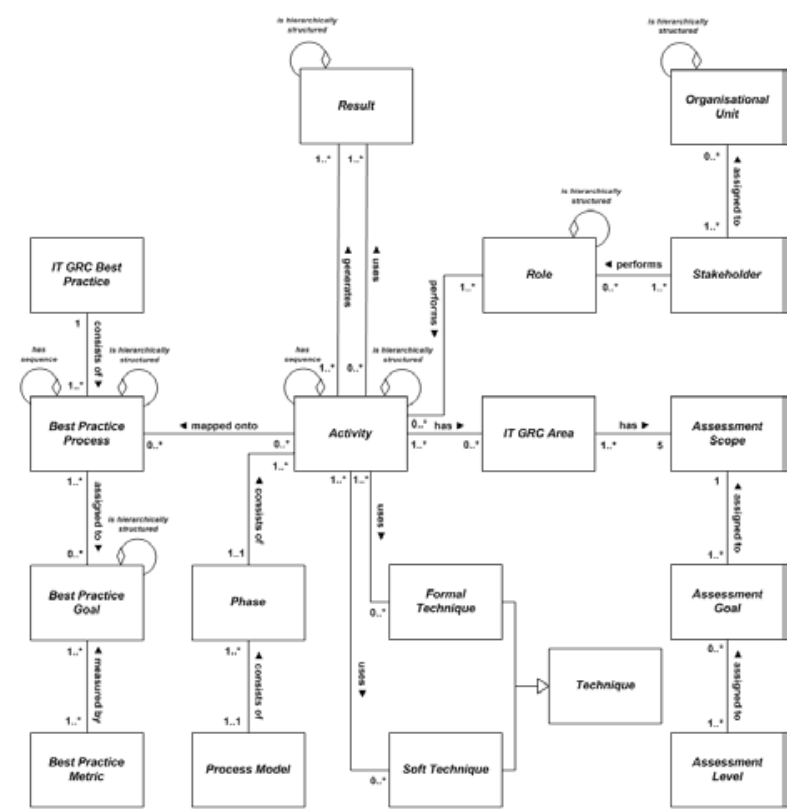

Figure 2: Meta-model of the method, based on [13] (p.13)

The method to be developed is understood as a structured guideline, which aims at enabling IT executives in hospitals to achieve greater value in the planning, implementation and control of IT GRC issues. In order to develop the method, two subordinated tasks are performed: (1) design and (2) construction of the method (cf. Figure 1). The construction of the method entails a content model (Section 4) and related concepts such as a process and assessment model ensuring that experts form the hospital environment can more likely understand and implement the method. This content model is presented in the next section.

\section{Content Model}

In the next sections, the documentation of the content model and its arrangements are presented. The arrangement of contents orientates oneself toward the defined process model and related phases according to [8].

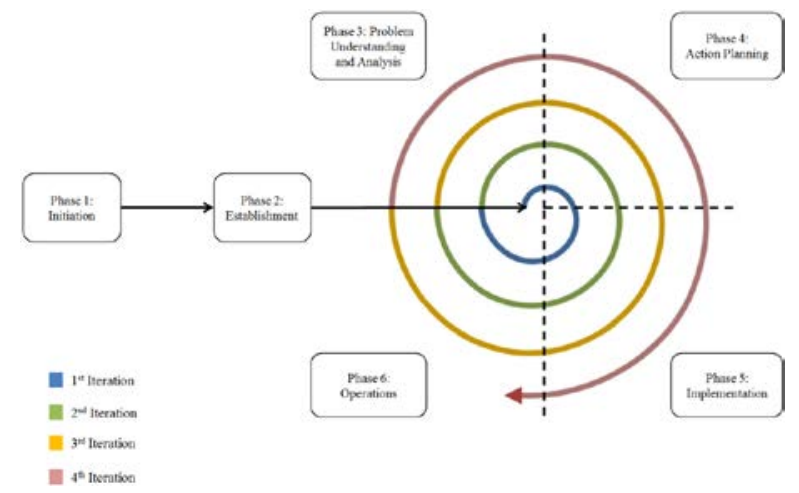

Figure 3: Process model for the adoption of IT GRC, based on the spiral model approach by [8]

The 'initiation phase' represents the initial setting of the process adopting IT GRC in the hospital environment. It is triggered by the 'felt-need' of a hospital or IT executive. The trigger may come from reform efforts, endeavors towards optimization of business processes or from external drivers such as cantonal legislative body or shareholders. Depending on the triggering party, the IT executive usually takes over the interim responsibility for the initial process setting. The setting of the initiative starts with the definition of an 'interim' project team that initially specifies a common understanding of IT GRC and its differentiation to other existing concepts and wordings within the hospital. Significant problems dealing with IT GRC such as inefficient mechanisms, undefined responsibilities, or missing structures in the alignment between business and IT are roughly identified and estimated by the project team contributing to a potential 'project idea'. Beside the investigation of issues related to IT GRC, an initial stakeholder analysis is performed, identifying related obstacles and power structures within the organization having inhibiting or enabling effects on potential initiatives. Ensuring management commitment to the initiative, a formal project proposal is developed, indicating quantified benefits, estimated costs, identified risks, provisional project planning, resources needed and 
interdependencies with other projects. Having the formal project charter obtained, a communication plan covering target stakeholders, mechanisms, channels, and schedules is developed. The phase is finalized by reviewing and documenting lessons learned.

After dealing with the concept of IT GRC within the IT department and having the initiative formally approved, the 'establishment phase' aims at the identification of a project sponsor and the on-going establishment of awareness for the initiative at related business stakeholders and committees. Assuming that changes provide a potential source of risk, 'change avoidance' and 'change tolerance' [29] within the hospital environment are combined. In doing so, the project environment, related stakeholders, power structures, encouraging and adverse influences are analyzed in more detail. Promoting the incremental change process in the hospital environment, a carefully considered way of communication reflects a central issue ensuring a successful change. Therefore, a project sponsor is identified, willing to bear and represent the initiative towards the business. The project idea, the related project team, and project plan are refined and adjusted according to the sponsor's needs. Promoting a common 'project spirit', a kick-off workshop is conducted providing the possibility to sort out frictions from previous projects, remove ambiguities and put the project team into the right mood.

After the two initial phases, the iterative part of the process begins. The 'problem understanding and analysis phase' starts in the innermost loop. Having the project sponsor identified and the project environment arranged, the third phase aims at the investigation of related IT GRC areas and their individual peculiarity according to five scopes, (1) roles, (2) responsibilities, (3) competences, (4) practices and (5) settings. Since IT GRC principles and related structures are less marked in the hospital environment, impacts and benefits are vague to assess. Making the hospital's individual assessment more transparent and understandable for the assessment user, goals are defined according to each scope indicating how well the organization has achieved this level in the wide array of IT GRC areas. The decoupled consideration of IT GRC areas reduces complexities, allows for building up and refining of knowledge, enhances the understanding and utilization of IT GRC principles, (e.g., stakeholder involvement, training of employees, communication, etc.), and improves indirectly the relationship between business and IT. Therefore, assessment levels ranging from 0 (non-existent) to 4 (optimized) are assigned to each area representing the current state dealing with IT GRC principles. In addition to the current state, the target state is defined for each area allowing for the identification of gaps and related issues, where improvements are needed. The problem understanding and analysis includes the consideration of a sector state (benchmark) related to each area providing guidance and orientation for hospitals with less expertise not over- or underengineer related issue compared to the sector average. In addition to the assessment of the 'formal' data, the interviews with the participants provide valuable insights about how the hospital and related organizational units actually have implemented IT GRC principles. They allow for the identification of areas that employees believe can and should be improved and support the assessment team in understanding relationships between business and IT from a technical and cultural perspective ('observations') [8]. A follow-up session is conducted to verify the data of every participant. The given similarities and different levels of granularity of the identified observations are balanced logically to core statements allowing for the later analysis.

Sharing the same view on the current state and having a set of areas and related issues, where improvements are needed identified, the 'action planning phase' aims at the derivation of smaller project packages preparing for the implementation of these issues. In doing so, the results from the problem understanding phase are balanced logically, reviewed and prioritized considering the observations from the interviews and related issues such as risk potentials, expected benefits, available resources, complexity or feasibility of the project. Having a prioritized project list established, a business case is developed and aligned with business and hospital strategy summarizing the expected benefits, estimated costs, identified risks, issues that come along with the implementation, resources needed, and project planning. Promoting the change process in the employee's mind and engaging additional project sponsors for different projects, the on-going communication using different channels and lobbying among the various stakeholders and related committees are maintained as central issues ensuring the successful change. In order to plan related projects and verify their expected benefits, a requirements analysis, a risk assessment, a stakeholder analysis, and an evaluation concept are conducted.

Within the 'implementation phase', the proposed solution is developed and validated. Depending on the purpose and scope of the project, the implementation may consider the establishment of new structures, processes, roles, responsibilities, the development of new products or only the alignment and customization of existing concepts. Promoting the employees empowerment dealing with IT GRC, stimulating the identification with related values and institutionalize 
new behaviors into the corporate culture, the implementation includes the generation of short-term wins through prototyping allowing employees to experiment [17]. In addition to the implementation of the project, the testing is performed and the transition into operational practice is planned. The planning of transition into day-to-day practice includes the schedule for the transition, the definition of related measures, and the establishment of mechanisms, roles, responsibilities, structures, and training. Ensuring the commitment from management and related funding, the 'transition plan' is finally presented to the hospital board of directors. Supporting the monitoring of related performance measures, related activities can be mapped onto existing best practices such as CObIT [11]. Improving the learning curve effect necessary for the second or third iteration of the loop, lessons learned are critically reviewed and project results are documented. Improving the on-going project marketing for IT GRC initializes, quick wins gained from the implementation are communicated across business stakeholders and committees.

Having the funding and commitment from management obtained, the innermost loop closes with the transition of the project into practice. The 'operations phase' ensures that related project results and benefits are sustainably considered and anchored within the hospital environment. Ensuring the new behaviors are institutionalized into the corporate hospital culture and that a constant change process is established, the defined measures are frequently monitored, roles and responsibilities are clearly assigned and controlled, and the outcomes are constantly optimized. Utilizing the gained experiences from the first iteration and having received positive feedbacks from on-going communication, project marketing and lobbying activities, the second loop starts with the identification of a related project sponsor conducting the problem understanding and analysis phase.

In the next section, the evaluation of the method is presented aiming at pointing out the methods utility through appropriate domain experts.

\section{Evaluation}

The evaluation includes the development of an evaluation process ensuring the method's applicability under real-world conditions. Although the importance and benefits of an evaluation are widely perceived in the field of IS, different definitions, understandings and emphases still can be found in literature [1]; [31].
However, an evaluation shall

- generate valid and reliable results,

- provide a rich mix of methods used for the data collection and

- $\quad$ shall be performed through an organized process.

Following the approach by [11] data triangulation is applied for this research work enhancing validity, reliability, and richness of the research results. Data triangulation aims at the gathering of evaluation data on a variety of different people. The involvement of different hospitals in terms of their ownership (i.e., public and fully private hospitals), and scope of work (i.e., centralized care level 1 and 2) from the Swiss health care sector is therefore intended. Based on the approach by the Swiss Federal Office of Public Health (FOPH) three health care institutions are selected [4]. Table 1 summarizes the configuration of the selected hospitals participating in the evaluation. The related information including level of care, ownership, number of employees, and beds, are anonymized at the request of the hospitals.

\section{Table 1: Information about hospitals participating} in the evaluation

\begin{tabular}{|l|c|c|c|}
\hline & Hospital A & Hospital B & Hospital C \\
\hline Level of care & $\begin{array}{c}\text { centralized care } \\
\text { level 1 }\end{array}$ & $\begin{array}{c}\text { centralized care } \\
\text { level 2 }\end{array}$ & $\begin{array}{c}\text { centralized care } \\
\text { level 2 }\end{array}$ \\
\hline Ownership & public & public & private \\
\hline $\begin{array}{l}\text { Number of } \\
\text { employees }\end{array}$ & 7.000 & 2.700 & 4.800 \\
\hline Number of beds & 920 & 530 & 1.400 \\
\hline $\begin{array}{l}\text { Number of } \\
\text { inpatient } \\
\text { (outpatient) }\end{array}$ & $37.000(273.000)$ & $25.000(105.000)$ & 80.000 (N/A) \\
\hline $\begin{array}{l}\text { Role of } \\
\text { participant }\end{array}$ & CIO & IT Manager & CIO \\
\hline $\begin{array}{l}\text { Organizational } \\
\text { structure }\end{array}$ & $\begin{array}{c}\text { functional } \\
\text { organization }\end{array}$ & matrix organization & affiliated doctors \\
\hline $\begin{array}{l}\text { Organization of } \\
\text { IT department }\end{array}$ & centralized & centralized & hybrid \\
\hline
\end{tabular}

In order to allow a profound statement of the value proposition of the developed IT GRC method and its related concepts from various perspectives the approach by [7] is applied. Demonstrating utility, the method is simulated and logical reasoned under realworld conditions within three different hospital environments using action research methodology.

Since Hospital A already has experience in dealing with IT GRC, the initiation and establishment phase are assessed as relevant. The openness of the project proposal activity and the possibility for it to be applied to the existing project standard PRINCE2 is considered valuable. However, for the establishment phase the level of formalisation of the method is assessed as very high, making a more pragmatic approach for daily business desirable. Having identified shortcomings with the help of the assessment model, the CIO made the decision to solve the problem immediately. As a short-term win, it was decided to develop an intranet 
site, outlining the significance of business and IT understanding, summarizing structures and competences of the different committees, and explaining related roles and responsibilities. It is expected that this approach will contribute to the transparency of the IT GRC approach towards business and have a positive side effect on the use of a common language.

The definition approach suggests that IT in Hospital B is all too often considered a fire brigade being responsible for the implementation of any kind of hard- or software that has been procured by the different organizational units. Having applied the assessment model in Hospital B, the interpretation of data reveals that settings for Business-IT-Alignment, such as aligned IT strategies are planned, but so far not defined, nor does a continuous monitoring of these issues exist. Similar to settings, the assessment of practices points out that harmonizing IT resources (e.g. clinical applications, IT project managers, infrastructure, etc.) with business objectives is performed on an unspecified and ad hoc basis. As a result, especially the clinical divisions seek to allocate IT resources exclusively for their needs, which results all too often in staff shortages, extra work, and frustration. In order to identify smaller project packages to improve the investigated assessment levels for business-IT alignment, the IT manager noted that for the realization of long-lasting measures arising from the analysis, it is important to adhere to certain rules specific for Hospital B. Thus, the department of corporate development has become involved in further endeavors towards improving IT GRC issues. From this time on, the project sponsor has been accountable for and assured the completeness and quality of the task. As a beneficial effect, related tasks of the subsequent establishment phase, such as coordinating and confirming estimated resources, or lobbying on behalf of the initiative, raise awareness at the management level since the head of the department of corporate development reports directly to the CEO.

Due to the fact that Hospital $\mathbf{C}$ already has experience in dealing with IT GRC, the initiation, and establishment phase are assessed as relevant, nevertheless, it is deliberately omitted from the application of the method. Starting, therefore, with the problem understanding and analysis phase, the application of the assessment model revealed that tasks related to IT value delivery are rudimentarily performed considering only priorities within given budgets. In order to establish a sustainable IT value delivery process for Hospital C, it is decided to perform related tasks on two different levels: (1) at the operational level as part of the project management approach and (2) as part of the strategic planning of IT capabilities at the corporate level. In order to assess the utility of CObIT 5, the process EDM02-Ensure Benefits Delivery is applied within the action planning phase. Related practices propose to evaluate the portfolio of IT-enabled investments (EDM02.01) and direct value management principles and practices (EDM02.02) [11] (p.36). Given the leadership structures in Hospital C, it was necessary to adjust the proposed roles and responsibilities in CObIT 5 . The original CObIT 5 approach has, therefore, been adapted making not the board of directors, but rather the CIO accountable for reviewing and assuring the completeness and quality of the practices (EDM02.01 and EDM02.02).

Given the gained knowledge from the case studies, the method is assessed as basically suitable for achieving the initially outlined objectives and its adoption in the hospital environment. It is pleasing to see, that neither the underlying organizational structure, nor the leadership approach necessarily influence the adoption of the method within the hospitals. The implementation of the method within Hospital B revealed that the method is also suitable for a bottom-up approach involving a great variety of stakeholders coming from different organizational units and hierarchical levels.

\section{Conclusion}

The evaluation of the method with a large statistical population, as often required for the evaluation of theories to empirically evidence the truth, is therefore only limited. Considering the application of the method as part of the evaluation, it becomes obvious that the derived opportunities affect the entire hospital environment, their effects, however, may not immediately perceptible, which may lead to a longterm and resource-intensive study and may therefore only be conducted in a few hospitals. The basic limitation of the evaluation approach was the use of a small statistical population constraining the representativeness and reliability of the results. Although all hospitals have assessed the learnability of the method as manageable in practice, the initial involvement of an IT GRC expert as part of the evaluation process contradicts, however, to the claimed objectivity of the evaluation results representing another limitation of the research. Although further evaluations with more hospitals are out of the scope of this research work, they are highly recommended for future research works.

Finally, the scope of the research work constitutes another limitation. The entire problem identification, specification of related requirements, method 
development, and evaluation focused on the Swiss hospital environment. Whether the method is applicable to different countries that share the same kinds of problems remains an open issue, however, its validation is highly recommended for future research works. The discussed health care systems in the United Kingdom (U.K.), Germany, and the United States (U.S.) make the placing of the situation and the discussion of derived challenges in the Swiss health systems according to an international context possible and allow for a preliminary estimate. The three outlined health care systems, in addition to the Swiss health system provide comprehensive insights into all kinds of systemizations ranging from state-run (U.K.), to social state principle (Germany), and on the other extreme, to a free market system (U.S.).

\section{References}

1. Alkin, Marvin C. A Guide for Evaluation Decision Makers. Beverly Hills, CA, USA: Sage, 1985.

2. Atkinson, Colin, and Kühne, Thomas. "Model-Driven Development: A Metamodeling Foundation.” IEEE Software 20, no. 5 (2003): 36-41.

3. Atkinson, Colin, and Kühne, Thomas. "Calling a Spade a Spade in the MDA Infrastructure." In Proceedings of the Metamodeling for MDA First International Workshop, 2003.

4. BAG. Statistiken zur Krankenversicherung: Kennzahlen der Schweizer Spitäler 2008/2009. Federal Office of Public Health (FOPH). Bern: Bundesamt für Gesundheit Sektion Statistik und Mathematik, 2011. http://www.bag-anw.admin.ch, accessed April 2017.

5. Banham, Russ. "Is ERM GRC? Or Vice Versa?”, 2007. http://www.treasuryandrisk.com, accessed April 2017.

6. Boehm, B. W. "A Spiral Model of Software Development and Enhancement.” Computer 21, no. 5 (1988): 61-72.

7. Bucher, Tobias, Riege, Christian, and Saat, Jan. "Evaluation in der gestaltungsorientierten

Wirtschaftsinformatik: Systematisierung nach Erkenntnisziel und Gestaltungsziel.” Heidelberg, Germany: Physica, 2008.

8. Bush, Marilyn, and Dunaway, Donna K. CMMI Assessments: Motivating Positive Change. Upper Saddle River, NJ, USA: Addison-Wesley, 2005

9. Crane, Robert M., and Raymond, Brian. "Fulfilling the Potential of Clinical Information Systems.” In The Permanente Journal, 2003.

10. Denzin, Norman K. The Research Act: A Theoretical Introduction to Sociological Methods. New Brunswick, NJ, USA: Aldine Transaction, 1970.

11. ISACA. CObIT 5: Enabling Processes. Rolling Meadows. IL, accessed September 2017.

12. Guba, Egon G., and Lincoln, Yvonna S. "Competing Paradigms in Qualitative Research.” In Handbook of Qualitative Research, edited by N. K. Denzin and Y. S. Lincoln. London, UK: Sage, 1994.

13. Gutzwiller, Thomas. Das CC-RIM-Referenzmodell für den Entwurf von betrieblichen, transaktionsorientierten Informationssystemen. Heidelberg, Germany: Physica-Verl., 1994.

14. Hardy, Catherine, and Leonard, Jenny. "Governance, Risk and Compliance (GRC): Conceptual Muddle and Technological Tangle.” In ACIS Proceedings, 2011.
15. Henderson, J. C., and Venkatraman, N. "Strategic Alignment: Leveraging Information Technology for Transforming Organizations.” IBM Systems Journal 32, no. 1 (1993): 4-16.

16. Hoerbst, Alexander, Hackl, Werner O., Blomer, Roland, and Ammenwerth, Elske. "The Status of IT Service Management in Health Care - ITIL ${ }^{\circledR}$ in Selected European Countries.” BMC Medical Informatics and Decision Making 11, no. 1 (2011): 7688.

17. Kotter, John P. Leading Change. Boston, MA, USA: Harvard Business School Press, 1996.

18. Köbler, Felix, Fähling, Jens, Krcmar, Helmut, and Leimeister, Jan. "IT Governance and Types of IT Decision Makers in German Hospitals.” Business \& Information Systems Engineering 2, no. 6 (2010): 359-370.

19. KPMG. "Governance, Risk, and Compliance. Driving Value through Controls Monitoring." 2008. www.kpmg.ca/itadvisory, accessed April 2017.

20. Krey, Mike, Harriehausen, Bettina, Knoll, Matthias, and Furnell, Steven. "IT Governance and its spread in Swiss Hospitals." In Proceedings of the IADIS International Conference e-Health, edited by Mário Macedo. Freiburg, Germany, 2010.

21. Lohmann, Heinz. "Erfolgsfaktor Medizin: Anforderungen an ein modernes Krankenhaus-management.” Berlin, Germany: Springer, 2009.

22. OMG. OMG Unified Modeling Language (OMG UML): Object Management Group, 2011. http://www.omg.org/, accessed April 2017.

23. OCEG. “GRC Capability Model: Red Book 2.1.” 2009. www.oceg.org/RedBook, accessed April 2017.

24. Porter, Michael E., and Teisberg, Elizabeth Olmsted. Redefining Health Care: Creating Value-Based Competition on Results. Boston, MA, USA: Harvard Business School, 2006.

25. PWC. "8th Annual Global CEO Survey." 2005. http://www.globes.co.il/Serve/Researches/documents/8thAnnual GlobalCEOSurvey.pdf, accessed April 2017.

26. Racz, Nicolas, Weippl, Edgar, and Seufert, Andreas. "A Frame of Reference for Research of Integrated Governance, Risk and Compliance (GRC).” In Lecture Notes in Computer Science, edited by David Hutchison. Berlin, Germany: Springer, 2010.

27. Racz, Nicolas, Weippl, Edgar, and Seufert, Andreas. "Governance, Risk \& Compliance (GRC) Software: An Exploratory Study of Software Vendor and Market Research Perspectives.” In Proceedings of the 44th Hawaii International Conference 2011: IEEE, 2011.

28. Selig, Gad J. Implementing IT governance: A Practical Guide to Global Best Practices in IT Management. 1st ed. Zaltbommel: Van Haren Pub., 2008.

29. Sommerville, Ian. Software Engineering. 9th ed. Boston: Pearson, 2011.

30. Strahringer, Susanne. Metamodellierung als Instrument des Methodenvergleichs: Eine Evaluierung am Beispiel objektorientierter Analysemethoden. Aachen, Germany: Shaker, 1996.

31. Stufflebeam, Daniel L., Foley, Walter J., Gephart, William J., Guba, Egon G., Hammond, Robert L., Marriman, Howard O., and Provus, Malcolm M. Educational Evaluation and Decision Making. 1st ed. Bloomington, Indiana: Phi Delta Kappa National Study Committee on Evaluation, 1971.

32. Vaishnavi, Vijay, and Kuechler, William. Design Science Research Methods and Patterns: Innovating Information and Communication Technology. Boca Raton: Auerbach Publications, 2008.

33. Weill, Peter, and Ross, Jeanne W. IT Governance: How Top Performers Manage IT Decision Rights for Superior Results. Boston, MA, USA: Harvard Business School Press, 2004.

34. Wegmüller, Bernhard, and Berger, Stefan. "The Swiss Healthcare System.” Healthcare IT Management 6, no. 3 (2011): pp. 43-45. 